\title{
A NEW INPUT-ORIENTED PLANT CAPACITY NOTION: DEFINITION AND EMPIRICAL COMPARISON*
}

\author{
Giovanni Cesaroni ${ }^{\dagger}$ \\ Kristiaan Kerstens \\ Ignace Van de Woestyne ${ }^{\S}$
}

\begin{abstract}
Starting from the existing output-oriented plant capacity measure, this paper proposes a new inputoriented plant capacity measure. Furthermore, we empirically illustrate both input- and outputoriented decompositions of technical efficiency integrating these technical concepts of capacity utilisation. In particular, we thereby pay attention to the impact of convexity of the technology on both input- and output-oriented plant capacity measures.
\end{abstract}

Keywords: efficiency; plant capacity utilisation, convexity.

* We thank a referee of this journal for his/her most constructive comments. The usual disclaimer applies.

$\dagger \quad$ Department for local development, Prime Minister's Office, Via della Mercede 9, IT00187 Rome, Italy.

$¥ \quad$ CNRS-LEM (UMR 9221), IESEG School of Management, 3 rue de la Digue, FR-59000 Lille, France. Tel: ++ 33(0)320545892, Fax: ++ 33(0)320574855, k.kerstens@ieseg.fr. Corresponding author.

$\S \quad$ KU Leuven, Research unit MEES, Warmoesberg 26, BE-1000 Brussel, Belgium. 


\section{INTRODUCTION}

Empirical studies on efficiency and productivity grounded in frontier specifications are abundantly available and these frontier methodologies have become standard empirical tools that serve a variety of academic, regulatory and managerial purposes. Apart from its prolific application in the academic literature analysing private and public sector performance-related issues (see, e.g., Liu et al. (2013) for a survey of empirical frontier applications), the implementation of incentive regulatory mechanisms using frontier-based performance benchmarks is rather widespread in liberalized network industries (e.g., for the electricity sector see the Jamasb and Pollitt (2001) survey). To cite but one example of a managerial application, the Sherman and Ladino (1995) study documents how a US bank employed a basic frontier model to find sufficient savings in its branch network to fund its strategy of expansion.

Many empirical applications take a long run perspective in that it is assumed that all inputs and/or outputs are under managerial control. While a focus on a sub-vector of, e.g., inputs is straightforward, the large majority of the frontier-based literature in fact ignores the notion of capacity utilisation. Consequently, a part of the measured amount of inefficiency may well be due to the short run fixity of some of the inputs. Recently, Caves (2007) argued that a variety of efficiency concepts and capacity notions have yielded a rich body of empirical knowledge on firm behaviour that is part of the so-called old industrial organisation literature. There are indeed many examples of empirical research on organisations focusing on capacity utilisation. For example, Ghemawat and Nalebuff (1985) have shown how the probability of firm survival depends on the ability to adjust capacity in order to keep production costs under control when facing changes in demand. Managing capacity utilisation smoothly is an organisational factor of strategic value.

This paper concentrates on the development of plant capacity measures using nonparametric frontier technologies. More specifically, this paper makes two contributions. First, it proposes a new input-oriented plant capacity measure that complements the existing output-oriented counterpart, as applied by, for instance, Valdmanis, Kumanarayake and Lertiendumrong (2004). Second, we empirically explore the differences between both these plant capacity notions using traditional convex as well as nonconvex technology specifications.

The paper is structured as follows. Section 2 offers a brief literature review on the different capacity notions around in the literature and their use in a nonparametric frontier context. It devotes some particular attention to the small literature having utilised the plant capacity concept. The next section introduces technologies and distance functions allowing to define the traditional outputoriented plant capacity measure as well as its new input-oriented counterpart. Then, the new inputoriented plant capacity measure is illustrated using a numerical example. An empirical section 
illustrates these new plant capacity measure for both convex and nonconvex nonparametric frontier technologies using a sample of Canadian farms specialising in milk production. Conclusions are drawn in a final section.

\section{LITERATURE REVIEW}

\subsection{Economic and Technical Capacity Utilisation: A Taxonomy}

The economic literature contains a variety of capacity notions. A useful taxonomy is to distinguish between technical (engineering) and economic (mainly cost-based) capacity concepts (see, e.g., Johansen (1968), Nelson (1989)). We first pay attention to the technical or engineering notion, and then to the economic concepts using a cost function approach. ${ }^{1}$

Johansen (1968) followed a technical approach by introducing the notion of plant capacity. ${ }^{2}$ Plant capacity is defined as the maximum output vector that can be produced with existing equipment with unrestricted variable inputs per unit of time. This capacity notion clearly takes an engineering perspective. Färe, Grosskopf and Kokkelenberg (1989) and Färe, Grosskopf and Valdmanis (1989) transpose this notion into a multi-output frontier framework using some combination of output efficiency measures (see also Färe, Grosskopf and Lovell (1994: § 10.3)).

At least three ways of defining a cost-based notion of capacity have been proposed in the literature (see Nelson (1989)). Each of these notions aims to isolate the short run excessive or inadequate utilisation of existing fixed inputs (for instance, capital stock). A first notion is defined in terms of the output produced at short run minimum average total cost given existing input prices (see Hickman (1964), among others). A second definition focuses on the output for which short and long run average total costs curves are tangent (e.g., Segerson and Squires (1990)). This tangency point notion is known under two variations depending on what are supposed to be the decision variables. One notion assumes that outputs are constant and determines optimal variable and fixed inputs. Another notion assumes that fixed inputs cannot adjust, but outputs, output prices and fixed input prices do adjust. A third and final definition of economic capacity considers the output determined by the minimum of the long run average total costs (for instance, Cassels (1937) and Klein (1960)). A brief summary of how these different economic capacity concepts can be transposed in a nonparametric frontier framework is found in De Borger et al. (2012).

One motivation for developing an input-oriented plant capacity measure is that it facilitates comparison with traditional and widely used economic notions based on the cost function. In this

\footnotetext{
${ }^{1}$ Briec et al. (2010) show that it is possible to develop dual capacity measures using nonparametric technologies for the case of other objective functions: e.g., profit maximisation (following Squires (1987)). The case of revenue maximisation (see Segerson and Squires (1995)) remains to be developed.

2 Johansen (1968) also proposes a synthetic capacity concept as the maximal output with existing plant and equipment while accounting for the restricted availability of variable inputs. This seems to correspond to technical efficiency.
} 
perspective, the currently available output-oriented plant capacity measure would then be more naturally compared with the more scarcely used revenue-based capacity notion (e.g., Segerson and Squires (1995)).

\subsection{Plant Capacity: A Selective Review}

Estimates of plant capacity have been reported regularly in the economic literature, though it is hard to deny that the notion of plant capacity is nowhere as popular as some of the cost-based notions of capacity. We offer a selection of plant capacity estimates in a variety of economic sectors.

Magnussen and Rivers Mobley (1999) compare Norwegian public and highly regulated hospitals to the Californian private and less regulated hospitals. Key findings are that the Norwegian hospitals have a higher plant capacity utilization, and that the excess capacity in California depends on competitive pressures. Karagiannis (2015) analyses Greek public hospitals in two distinct years (1993 and 2002), while Kerr et al. (1999) estimate plant capacity of 23 acute hospitals in Northern Ireland comparing two three year periods. Valdmanis, Bernet and Moises (2010) compute statewide hospital capacity in Florida based on the whole hospital population as part of an emergency preparedness plan. Starting from a scenario involving patient evacuations from Miami due to a major hurricane event, they assess whether hospitals in proximity to the affected market can absorb the excess patient flow. Finally, Valdmanis, Kumanarayake and Lertiendumrong (2004) estimate plant capacity utilisation in 68 Thai public hospitals in 1999 with a focus on the eventual trade-offs between services for the poor and the nonpoor. They find that hospitals are generally operating at relatively high capacity (90-95 percent) and that there is no significant difference between capacity utilization across three types of hospitals and across different regions.

Felthoven (2002) analyses the impact of the American Fisheries Act (AFA) of 1998 on the Pollock fishery and finds that decommissioned vessels exhibited a lower level of technical efficiency and that the capacity utilization of the AFA-eligible vessels increased after the law came into effect. Kirkley, Morrison Paul and Squires (2002) focus on the US North Atlantic sea scallop fishery centered in Georges Bank and various Mid-Atlantic resource areas with as dominant gear type the dredge. They report a plant capacity of about $33 \%$ using stochastic frontiers and a $22 \%$ rate with a nonparametric model, while there does not seem to be a clear trend in plant capacity over time. Van Hoof and De Wilde (2005) estimate capacity of the Dutch beam-trawling fleet over the period 1992-99 finding an overall average of 0.83 plant capacity. They also explain the variations in plant capacity by a dummy for the home port, the price of plaice, the quotas for sole, the spawning stock for both plaice and sole, and the fleet sizes. Vestergaard, Squires and Kirkley (2003) obtain for a 
small sample of 69 Danish gill-net vessels in 1993 a high average plant capacity score of 0.92. Walden and Tomberlin (2010) estimate plant capacity for 71 steel-hulled vessels using bottom trawl gear fishing off the northeastern US coast in the Exclusive Economic Zone during 2006. They find an overall capacity utilization rate using a convex model of only $52 \%$, while a nonconvex model obtains a rate of $84 \%$ : the latter result is deemed more credible.

Apart from these studies focusing on health care and fisheries, we are only aware of one study focusing on another economic sector. Indeed, Sahoo and Tone (2009) analyse plant capacity as well as other capacity notions for the Indian banking sector. All these studies hide a large variation in methodological choices. For instance, Felthoven (2002) and Kirkley, Morrison Paul and Squires (2002) estimate plant capacity using both nonparametric and stochastic frontier analysis. As another example, while many articles limit themselves to just measuring plant capacity, Karagiannis (2015) as well as Van Hoof and De Wilde (2005) also explain the variations in plant capacity using different regression methods. As a final case, Vestergaard, Squires and Kirkley (2003) also develop partial plant capacity measures using output-specific nonradial efficiency measures.

These plant capacity estimates have also been used as parameters in a so-called short-run industry model attempting to reallocate outputs and resources across production units so as to reduce excess capacity levels at the industry level. Dervaux, Kerstens and Leleu (2000) apply such a model to reorganize French surgery units, while Kerstens, Vestergaard and Squires (2006), Van Hoof and De Wilde (2005) as well as Yagi and Managi (2011) explore its application in a fishery context. Another methodological refinement based on the plant capacity notion is its inclusion in a decomposition of the Malmquist productivity index (see De Borger and Kerstens (2000) and the extension by Bye, Bruvoll and Larsson (2009)).

\section{PLANT CAPACITY: DEFINITIONS}

\subsection{Distance Functions, Efficiency Measures and Plant Capacity Notions}

\subsubsection{Distance Functions and Efficiency Measures}

To clear the ground, we start by defining technology and some basic notation. Denoting an $n$ dimensional input vector $\left(x \in \mathbb{R}^{\mathrm{n}_{+}}\right)$and an $m$-dimensional output vector $\left(y \in \mathbb{R}^{\mathrm{m}_{+}}\right)$, the production possibility set or technology is defined as follows: $S=\{(x, y) \mid x$ can produce $y\}$. The input set associated with $S$ denotes all input vectors $x \in \mathbb{R}^{\mathrm{n}}{ }_{+}$capable of producing a given output vector $y \in$ $\mathbb{R}^{\mathrm{m}}{ }_{+}: L(y)=\{x \mid(x, y) \in S\}$. In an analogous way, the output set associated with $S$ denotes all output

vectors $y \in \mathbb{R}^{\mathrm{m}}{ }_{+}$that can be produced from a given input vector $x \in \mathbb{R}_{+}^{\mathrm{n}_{+}}: P(x)=\{\mathrm{y} \mid(x, y) \in S\}$. 
Furthermore, it is often useful to partition the input vector into a fixed and variable part $\left(x=\left(x^{f}, x^{\nu}\right)\right)$. By analogy, we define a short-run technology $S^{f}=\left\{\left(x^{f}, y\right) \mid x^{f}\right.$ can produce $\left.y\right\}$ and the corresponding input set $L^{f}(y)=\left\{x^{f} \mid\left(x^{f}, y\right) \in S^{f}\right\}$ and output set $P^{f}\left(x^{f}\right)=\left\{y \mid\left(x^{f}, y\right) \in S^{f}\right\}$.

The input distance function offers a complete characterization of the input set $L(y)$ and is defined as follows:

$$
D_{i}(x, y)=\max \{\gamma: \gamma \geq 0, x / \gamma \in L(y)\} .
$$

Next, one can define the radial input efficiency measure as:

$$
D F_{i}(x, y)=\min \{\lambda \mid \lambda \geq 0, \lambda x \in L(y)\} .
$$

The latter measure is the inverse of the input distance function $\left(D F_{i}(x, y)=\left[D_{i}(x, y)\right]^{-1}\right)$. Its main properties (e.g., Hackman (2008)) are that it is situated between zero and unity $\left(0<D F_{i}(x, y) \leq 1\right)$, with efficient production on the boundary (isoquant) of the input set $L(y)$ represented by unity. Furthermore, the radial input efficiency measure has a cost interpretation.

The output distance function offers a complete characterization of the output set $P(x)$ and it can be defined as follows:

$$
D_{o}(x, y)=\min \{\mu: \mu \geq 0, y / \mu \in P(x)\} .
$$

Next, one can define the radial output efficiency measure as:

$$
D F_{o}(x, y)=\max \{\theta: \theta \geq 0, \theta y \in P(x)\} .
$$

The latter measure is the inverse of the output distance function $\left(D F_{o}(x, y)=\left[D_{o}(x, y)\right]^{-1}\right){ }^{3}$ Its main properties (e.g., Hackman (2008)) are that it is larger than or equal to unity $\left(D F_{o}(x, y) \geq 1\right)$, with efficient production on the boundary (isoquant) of the output set $P(x)$ represented by unity. Furthermore, the radial output efficiency measure has a revenue interpretation. By analogy, denote the output distance function and radial output efficiency measure of the short-run output set $P^{f}\left(x^{f}\right)$ by $D_{o}^{f}\left(x^{f}, y\right)$ and $D F_{o}^{f}\left(x^{f}, y\right)$ respectively. Then, $D_{o}^{f}\left(x^{f}, y\right)=\min \left\{\mu: \mu \geq 0, y / \mu \in P^{f}\left(x^{f}\right)\right\}$ and $D F_{o}^{f}\left(x^{f}, y\right)=\max \left\{\theta: \theta \geq 0, \theta y \in P^{f}\left(x^{f}\right)\right\}$.

\subsubsection{Output-Oriented Plant Capacity Utilisation}

We now first recall the definition of the output-oriented plant capacity utilisation measure (see Färe, Grosskopf and Kokkelenberg (1989) and Färe, Grosskopf and Valdmanis (1989)). An output-oriented measure of plant capacity utilisation requires solving an output efficiency measure

\footnotetext{
${ }^{3}$ There are also definitions around in the literature whereby the output-oriented efficiency measure equals the output distance function.
} 
relative to both a standard technology and the same technology without restrictions on the availability of variable inputs. Plant capacity utilisation in the outputs $\left(P C U_{o}\left(x, x^{f}, y\right)\right)$ is defined as:

$$
P C U_{o}\left(x, x^{f}, y\right)=\frac{D F_{o}(x, y)}{D F_{o}^{f}\left(x^{f}, y\right)}
$$

where $D F_{o}(x, y)$ and $D F_{o}^{f}\left(x^{f}, y\right)$ are output efficiency measures relative to technologies including respectively excluding the variable inputs as defined before. Notice that $0<P C U_{o}\left(x, x^{f}, y\right) \leq 1$, since $1 \leq D F_{o}(x, y) \leq D F_{o}^{f}\left(x^{f}, y\right)$. Thus, output-oriented plant capacity utilisation has an upper limit of unity, but no lower limit.

This leads to the following basic output-oriented decomposition:

$$
D F_{o}(x, y)=D F_{o}^{f}\left(x^{f}, y\right) \cdot P C U_{o}\left(x, x^{f}, y\right) .
$$

Thus, the traditional output-oriented efficiency measure $D F_{o}(x, y)$ can be decomposed into a biased plant capacity measure $D F_{o}^{f}\left(x^{f}, y\right)$ and an unbiased plant capacity measure $P C U_{o}\left(x, x^{f}, y\right)$, following the terminology introduced by Färe, Grosskopf and Kokkelenberg (1989), Färe, Grosskopf and Valdmanis (1989) and Färe, Grosskopf and Lovell (1994). We explain these notions with the help of Figure 1.

Figure 1 tries to develop the intuition behind both the output- and input-oriented plant capacity measures in a single variable input and output space. The total product curve for given fixed inputs is the polyline $a b c d$ and its horizontal extension at $d$. Observations are denoted by squares, projection points by circles. We focus on observation $e$. We start by explaining the geometric intuition behind the output-oriented plant capacity measure and its components.

\section{$<$ FIGURE 1 ABOUT HERE>}

The output-oriented plant capacity measure compares point $e$ to its vertical projection point $e^{\prime \prime \prime}$ on the frontier on the line segment $c d$, and also compares the translated point $e^{\prime}$ (which consumes more variable inputs) to its vertical projection point on the horizontal frontier segment emanating from point $d$ with maximal outputs. The traditional output-oriented efficiency measure $D F_{o}(x, y)$ is therefore represented by the ratio of distances $0^{\prime \prime} e^{\prime \prime \prime} / 0^{\prime \prime} e(\geq 1)$. The biased plant capacity measure $D F_{o}^{f}\left(x^{f}, y\right)$ starts measuring from the translated point $e^{\prime}$. This translated point has an identical output level as point $e$, but without constraints on its amount of variable inputs it manages to generate the maximum output level at point $d$. Therefore, the biased plant capacity measure $D F_{o}^{f}\left(x^{f}, y\right)$ is represented by the ratio of distances $O^{\prime} d / O^{\prime} e^{\prime}(\geq 1)$. This biased plant capacity measure correctly reveals the maximal output available (represented by point $d$ ), but it still starts from an inefficient point (represented by point $e$ ). The unbiased plant capacity measure $P C U_{o}\left(x, x^{f}, y\right)$, as the ratio of both these efficiency measures, is represented by the ratio of 
distances $\left(0^{\prime \prime} e^{\prime \prime \prime} / 0^{\prime \prime} e\right) /\left(O^{\prime} d / O^{\prime} e^{\prime}\right)$. Since the ratios $O^{\prime \prime} e$ and $O^{\prime} e^{\prime}$.are identical, this simplifies to the ratio $0^{\prime \prime} e^{\prime \prime \prime} / 0^{\prime} d(\leq 1)$. Thus, the unbiased plant capacity measure correctly compares the maximum output $e^{\prime \prime \prime}$ that can be reached starting from point $e$ with the maximal output $d$ that can be reached starting from the translated point $e^{\prime}$. The exact position of point $e$ (or its translation $e^{\prime}$ ) and thus its efficiency status does not influence this plant capacity measurement for a given level of variable inputs. The maximal output $d$ can be labelled the plant capacity output. Obviously, this unbiased plant capacity measure $P C U_{o}\left(x, x^{f}, y\right)$ is linked to the distance $e^{\prime \prime \prime} d^{\prime}$, where the point $d^{\prime}$ is the translation from the maximal output at point $d$ to the output level comparable with point $e$.

We can now also explain why $0<P C U_{o}\left(x, x^{f}, y\right) \leq 1$. Imagine that point $e$ would shift somewhat to the right (say anywhere on the line segment $e e^{\prime}$, but not to point $e^{\prime}$ ) and be capable to generate a somewhat higher maximal output than the one indicated by point $e^{\prime \prime \prime}$. Then, the distance to the plant capacity output (point $d$ ) would become shorter than the distance $e^{\prime \prime \prime} d$ ' and hence $P C U_{o}\left(x, x^{f}, y\right)$ would increase. Obviously, the reverse would be true if point $e$ would shift somewhat to the left and be capable to generate a somewhat lower maximal output than the one indicated by point $e^{\prime \prime \prime}:$ then, $P C U_{o}\left(x, x^{f}, y\right)$ would decrease.

We can now also explain when $P C U_{o}\left(x, x^{f}, y\right)=1$ : imagine that point $e$ would shift to the right to point $e^{\prime}$, then the distance $e^{\prime \prime \prime} d^{\prime}$ would vanish. Otherwise stated, in this case there is no longer any difference between the traditional output-oriented efficiency measure $D F_{o}(x, y)$ and the biased plant capacity measure $D F_{o}^{f}\left(x^{f}, y\right)$ : both would measure an identical ratio of distances, hence $P C U_{o}\left(x, x^{f}, y\right)$ becomes unity. Note that the latter result is independent of the efficient or inefficient nature of the point considered, since we have already shown that the efficiency status does not influence plant capacity measurement. Thus, the output-oriented plant capacity utilisation has an upper limit of unity, but no lower limit (i.e., this lower limit is determined by the empirical configuration of the data).

\subsubsection{Input-Oriented Plant Capacity Utilisation: A New Definition}

We now turn to the new definition of the input-oriented plant capacity measure. Plant capacity utilisation in the inputs $\left(P C U_{i}\left(x, x^{f}, y\right)\right)$ is defined as:

$$
P C U_{i}\left(x, x^{f}, y\right)=\frac{D F_{i}^{S R}\left(x^{f}, x^{v}, y\right)}{D F_{i}^{S R}\left(x^{f}, x^{v}, 0\right)},
$$

where $D F_{i}^{S R}\left(x^{f}, x^{v}, y\right)$ and $D F_{i}^{S R}\left(x^{f}, x^{v}, 0\right)$ are both sub-vector input efficiency measures reducing only the variable inputs relative to the technology, whereby the latter efficiency measure is evaluated at a zero output level. Obviously, this requires the following three definitions: 
$D F_{i}^{S R}\left(x^{f}, x^{v}, y\right)=\min \left\{\lambda: \lambda \geq 0,\left(x^{f}, \lambda x^{v}\right) \in L(y)\right\}$ is a sub-vector input efficiency measure reducing variable inputs, $L(0)=\{x \mid(x, 0) \in S\}$ is the input set with zero output level, and $D F_{i}^{S R}\left(x^{f}, x^{v}, 0\right)=\min \left\{\lambda: \lambda \geq 0,\left(x^{f}, \lambda x^{v}\right) \in L(0)\right\}$ is the sub-vector input efficiency measure reducing variable inputs evaluated relative to this input set with a zero output level. Notice that $P C U_{i}\left(x, x^{f}, y\right) \geq 1$, since $0 \leq D F_{i}^{S R}\left(x^{f}, x^{v}, 0\right) \leq D F_{i}^{S R}\left(x^{f}, x^{v}, y\right) \leq 1$. Thus, input-oriented plant capacity utilisation has a lower limit of unity, but no upper limit.

This leads to the basic input-oriented decomposition:

$$
D F_{i}^{S R}\left(x^{f}, x^{v}, y\right)=D F_{i}^{S R}\left(x^{f}, x^{v}, 0\right) \cdot P C U_{i}\left(x, x^{f}, y\right) .
$$

Thus, the traditional sub-vector input-oriented efficiency measure $D F_{i}^{S R}\left(x^{f}, x^{v}, y\right)$ is decomposed into a biased plant capacity measure $D F_{i}^{S R}\left(x^{f}, x^{v}, 0\right)$ and an unbiased plant capacity measure $P C U_{i}\left(x, x^{f}, y\right)$. We explain the geometric intuition behind these notions in two steps: the basic relations are developed with the help of Figure 1, and the need for sub-vector variable inputoriented efficiency measures in defining the input-oriented plant capacity measure is explained with the help of Figure 2.

The sub-vector input-oriented plant capacity measure compares point $e$ to its horizontal projection point $e^{\prime \prime \prime \prime}$ on the frontier on the line segment $b c$, and also compares the translated point $e^{\prime \prime}$ (which consumes equal amounts of variable inputs but yields a zero output level) to its horizontal projection point on the vertical frontier segment $a b$ with zero outputs. The traditional sub-vector input-oriented efficiency measure $D F_{i}^{S R}\left(x^{f}, x^{v}, y\right)$ is therefore represented by the ratio of distances $O^{\prime \prime \prime} e^{\prime \prime \prime \prime} / 0^{\prime \prime \prime} e(\leq 1)$. The biased sub-vector plant capacity measure $D F_{i}^{S R}\left(x^{f}, x^{v}, 0\right)$ starts measuring from the translated point $e^{\prime \prime}$. This translated point has identical variable inputs compared to point $e$, but has a zero output level: it manages to generate the minimum output level at point $a$ above which positive output production levels start. Therefore, the biased plant capacity measure $D F_{i}^{S R}\left(x^{f}, x^{v}, 0\right)$ is represented by the ratio of distances $0 a / 0 e^{\prime \prime}(\leq 1)$. This plant capacity measure correctly reveals the minimal variable input level available (represented by point $a$ ) for a given minimal (=zero) output level, but it still starts from an inefficient point (represented by point $e^{\prime \prime}$ ). The unbiased plant capacity measure $P C U_{i}\left(x, x^{f}, y\right)$, as the ratio of both these efficiency measures, is represented by the ratio of distances $\left(0^{\prime \prime} e^{\prime \prime \prime \prime} / 0^{\prime \prime \prime} e\right) /\left(0 a / 0 e^{\prime \prime}\right)$. Since the ratios $0 e^{\prime \prime}$ and $O^{\prime \prime \prime} e$ are identical, this simplifies to the ratio $O^{\prime \prime \prime} e^{\prime \prime \prime \prime} / 0 a(\geq 1)$. Thus, the unbiased plant capacity measure correctly compares the minimal amount of variable inputs $e^{\prime \prime \prime}$ compatible with current output levels starting from point $e$ with the minimal amount of variable inputs $a$ compatible with a zero output 
level starting from the translated point $e^{\prime \prime}$. The exact position of point $e$ (or its translation $e^{\prime \prime}$ ) and thus its efficiency status does not influence this plant capacity measurement for a given level of outputs. The minimal (in casu zero) output $a$ can be labelled the plant capacity output. Evidently, this unbiased plant capacity measure $P C U_{i}\left(x, x^{f}, y\right)$ is linked to the distance $b^{\prime} e^{\prime \prime \prime \prime}$, where the point $b^{\prime}$ is the translation from the output at point $b$ to the output level comparable with point $e$.

We are now also in a position to explain why $0<P C U_{i}\left(x, x^{f}, y\right) \leq 1$. Imagine that point $e$ would shift somewhat up (say anywhere on the line segment $e e^{\prime \prime \prime}$ ) and be capable to generate a somewhat higher minimal variable input than the one indicated by point $e^{\prime \prime \prime \prime}$. Then, the distance to the plant capacity output (point $a$ ) would become larger than the distance $b^{\prime} e^{\prime \prime \prime}$ and hence $P C U_{i}\left(x, x^{f}, y\right)$ would increase. Obviously, the reverse would be true if point $e$ would shift somewhat below and be capable to generate a somewhat lower variable input than the one indicated by point $e^{\prime \prime \prime \prime}$ : then, $P C U_{i}\left(x, x^{f}, y\right)$ would decrease.

We can now also explain when $P C U_{i}\left(x, x^{f}, y\right)=1$ : imagine that point $e$ would shift below to point $e^{\prime \prime}$, then the distance $b^{\prime} e^{\prime \prime \prime \prime}$ would vanish. Otherwise stated, in this case there is no longer any difference between the traditional sub-vector input-oriented efficiency measure $D F_{i}^{S R}\left(x^{f}, x^{\nu}, y\right)$ and the biased plant capacity measure $D F_{i}^{S R}\left(x^{f}, x^{v}, 0\right)$ : both would measure an identical ratio of distances, hence $P C U_{i}\left(x, x^{f}, y\right)$ becomes unity. Note that the latter result is independent of the efficient or inefficient nature of the point considered, since we have already shown that the efficiency status does not influence plant capacity measurement. Thus, the input-oriented plant capacity utilisation measure has a lower limit of unity, but no upper limit (i.e., this upper limit is determined by the empirical configuration of the data).

Figure 2 develops the geometric intuition behind the need for sub-vector variable inputoriented efficiency measures in defining the input-oriented plant capacity measure. The isoquant denoting the combinations of fixed and variable inputs yielding a given output level $L(y)$ is represented by the polyline $a b c d$ and its vertical and horizontal extensions at $a$ and $d$ respectively. We focus on observation $e$ to illustrate first the output-oriented plant capacity utilisation measure: for a given fixed input vector, it scales up the use of variable inputs to reach a translated point $e^{\prime}$ that allows maximizing the vector of outputs. For the development of the input-oriented plant capacity measure, it therefore seems logical to look for a reduction in variable inputs for given fixed inputs towards the translated point $e^{\prime \prime}$ that is situated outside the isoquant $L(y)$ because it produces an output vector of zero (it is compatible with the isoquant $L(0)$ that is situated lower).

\section{<FIGURE 2 ABOUT HERE>}

In brief, while the output-oriented plant capacity measure evaluates capacity by contrasting the frontier outputs for a given observation with respect to the maximal outputs available 
(represented by the horizontal segment starting at point $d$ of the frontier in Figure 1) net of inefficiency, the input-oriented plant capacity measure assesses capacity by contrasting the minimum variable inputs for an observation with given outputs with respect to the minimal variable inputs for a translated observation producing a zero output (represented by point $a$ on the vertical segment $a b$ of the frontier in Figure 1), also net of inefficiency. Otherwise stated, while the outputoriented plant capacity measure compares output levels relative to the maximum level of outputs available, the input-oriented plant capacity measure compares variable input levels relative to the amount of variable inputs compatible with a zero output level.

\subsection{Nonparametric Technologies: Definitions}

The choice for nonparametric frontier technologies is related to the fact that primal capacity notions (like plant capacity) are difficult to estimate using traditional parametric specifications. ${ }^{4}$ Therefore, plant capacity is measured relative to a nonparametric frontier technology imposing strong disposability in inputs and outputs and assuming variable returns to scale:

$$
S^{C}=\left\{(x, y): \quad x \geq \sum_{k=1}^{K} x_{k} z_{k}, y \leq \sum_{k=1}^{K} y_{k} z_{k}, \sum_{k=1}^{K} z_{k}=1, z_{k} \geq 0\right\} .
$$

In view of the importance of nonconvexities in production stressed in Tone and Sahoo (2003) and confirmed in the context of plant capacity estimation by Walden and Tomberlin (2010), we also employ a nonconvex variable returns to scale technology:

$$
S^{N C}=\left\{(x, y): \quad x \geq \sum_{k=1}^{K} x_{k} z_{k}, y \leq \sum_{k=1}^{K} y_{k} z_{k}, \sum_{k=1}^{K} z_{k}=1, z_{k} \in\{0,1\}\right\},
$$

which only differs from the previous technology in that the activity vector $(z)$ is restricted to be binary integer.

For the sake of clarity, we explicitly add the two linear programming models that need to be computed in order to obtain the traditional output-oriented plant capacity measure. To simplify matters, we only treat the case of the traditional convex technology (9): the case of the nonconvex technology (10) is similar. For an evaluated observation $\left(x^{o}, y^{o}\right)$, one can obtain the radial output measure $D F_{o}(x, y)$ as follows:

\footnotetext{
${ }^{4}$ For instance, Färe (1984) shows that a primal capacity notion cannot be obtained for certain popular parametric specifications of technology (e.g., the Cobb-Douglas).
} 


$$
\begin{aligned}
D F_{o}\left(x^{o}, y^{o}\right) & =\max _{\theta, z} \theta \\
\text { s.t. } \quad \sum_{k=1}^{K} y_{k m} z_{k} & \geq \theta y_{m}^{o} \quad m=1, \ldots, M, \\
\sum_{k=1}^{K} x_{k n} z_{k} & \leq x_{n}^{o} \quad n=1, \ldots, N, \\
\sum_{k=1}^{K} z_{k} & =1, \\
z_{k} & \geq 0, \theta \geq 0, \quad k=1, \ldots, K .
\end{aligned}
$$

The efficiency measure $D F_{o}^{f}\left(x^{f}, y\right)$ is computed for observation $\left(x^{o}, y^{o}\right)$ as:

$$
\begin{gathered}
D F_{o}^{f}\left(x^{f o}, y^{o}\right)=\max _{\theta, z} \theta \\
\text { s.t. } \quad \sum_{k=1}^{K} y_{k m} z_{k} \geq \theta y_{m}^{o} \quad m=1, \ldots, M, \\
\sum_{k=1}^{K} x_{k n}^{f} z_{k} \leq x_{n}^{f o} \quad n=1, \ldots, N^{f}, \\
\sum_{k=1}^{K} z_{k}=1,
\end{gathered}
$$

$$
z_{k} \geq 0, \theta \geq 0, \quad k=1, \ldots, K .
$$

Note that there are no input constraints on the variable inputs.

Turning now to the new input-oriented plant capacity measure, one computes the radial subvector input measure $D F_{i}^{S R}\left(x^{f}, x^{v}, y\right)$ for an evaluated observation $\left(x^{o}, y^{o}\right)$ as follows:

$$
\begin{aligned}
D F_{i}^{S R}\left(x^{f o}, x^{v o}, y^{o}\right) & =\min _{\lambda, z} \lambda \\
\text { s.t. } \quad \sum_{k=1}^{K} y_{k m} z_{k} & \geq y_{m}^{o} \quad m=1, \ldots, M, \\
\sum_{\mathrm{k}=1}^{\mathrm{K}} x_{k n}^{f} z_{k} & \leq x_{n}^{f o} \quad n=1, \ldots, N^{f}, \\
\sum_{\mathrm{k}=1}^{\mathrm{K}} x_{k n}^{v} z_{k} & \leq \lambda x_{n}^{v o} \quad n=1, \ldots, N^{v}, \quad N^{f}+N^{v}=N, \\
\sum_{k=1}^{K} z_{k} & =1, \\
z_{k} & \geq 0, \lambda \geq 0, \quad k=1, \ldots, K .
\end{aligned}
$$

The sub-vector efficiency measure $D F_{i}^{S R}\left(x^{f}, x^{v}, 0\right)$ is obtained for observation $\left(x^{o}, y^{o}\right)$ by solving: 


$$
\begin{aligned}
D F_{i}^{S R}\left(x^{f o}, x^{v o}, 0\right) & =\min _{\lambda, z} \lambda \\
\text { s.t. } \quad \sum_{k=1}^{K} y_{k m} z_{k} & \geq 0 \quad m=1, \ldots, M, \\
\sum_{\mathrm{k}=1}^{\mathrm{K}} x_{k n}^{f} z_{k} & \leq x_{n}^{f o} \quad n=1, \ldots, N^{f}, \\
\sum_{\mathrm{k}=1}^{\mathrm{K}} x_{k n}^{v} z_{k} & \leq \lambda x_{n}^{v o} \quad n=1, \ldots, N^{v}, \quad N^{f}+N^{v}=N, \\
\sum_{k=1}^{K} z_{k} & =1, \\
z_{k} & \geq 0, \lambda \geq 0, \quad k=1, \ldots, K .
\end{aligned}
$$

Note that the observed output levels on the right hand side of the output constraints are set equal to zero. The determination of input utilization rates for the variable inputs is straightforward in the output-oriented case (e.g., Färe, Grosskopf and Lovell (1994: § 10.3)), the determination of optimal variable inputs is equally trivial in this input-oriented case.

Comparing the linear programs (11) to (14) two key observations can be made. First, the radial output efficiency measure in (11) and (12) looks for expansions in all output dimensions, while the radial input efficiency measure in (13) and (14) looks for reductions in the variable inputs only, while accounting for the input constraints related to the fixed inputs. The latter is in line with the need for a sub-vector approach explained in Figure 2 above. Second, the linear program in (12) is different from the linear program in (11) in that no input constraints related to the variable input dimensions are included. In terms of Figure 1, the purpose of removing the constraints with the current allocation of variable inputs is to be able to translate the observation $e$ into the direction of point $e^{\prime}$ in an effort to seek the maximum output available in point $d$. The linear program in (14) is different from the linear program in (13) in that the output constraints are now set at a zero level. In terms of Figure 1, the sub-vector efficiency measure looks for reductions in variable inputs to be able to translate the observation $e$ into the direction of point $e^{\prime \prime \prime}$ and beyond in an effort to seek the minimum amount of variable inputs compatible with a zero output level at point $a$.

\section{NUMERICAL ILLUSTRATION}

Consider a numerical example with a single fixed input, two variable inputs and a single output containing 16 observations. The data is provided in the first five columns of Table 1 . The projection of the efficient frontier (assuming a convex technology) in the input-output space containing the two variable input dimensions and the output dimension is illustrated in Figure 3. For this illustration, fixed input is set to a high enough value (at least 3 with the current data) to assure all observations being considered in the construction of the frontier. The frontier is made slightly 
transparent allowing to observe interesting points behind this frontier. All initial observations are clearly visible except for those occluded by the vertical plane.

To illustrate the new input-oriented capacity utilization measure (7), consider the additional point $a$ in Figure 3 with $x^{f}=3, x^{v}=(7,5)$ and $y=4$. The short run efficiency occurring in the numerator of (7) is computed using model (13). For point $a$, this results in $D F_{i}^{S R}\left(\bar{x}^{f}, x^{v}, y\right)=0.7910$ indicating the allowable radial contraction of the variable inputs. When applied, this contraction leads to point $b$ in Figure 3. In fact, $D F_{i}^{S R}\left(x^{f}, x^{v}, y\right)=\frac{|c b|}{|c a|}$. The short run efficiency in the denominator of (7) is obtained using model (14). For point $a$, this yields $D F_{i}^{S R}\left(x^{f}, x^{v}, 0\right)=0.6119$. This value can be observed in Figure 3 as the ratio $D F_{i}^{S R}\left(x^{f}, x^{v}, 0\right)=\frac{|o e|}{|o d|}$. Combination of both efficiencies using (7) leads to the input-oriented capacity utilization:

$$
P C U_{i}\left(x, x^{f}, y\right)=\frac{D F_{i}^{S R}\left(x^{f}, x^{v}, y\right)}{D F_{i}^{S R}\left(x^{f}, x^{v}, 0\right)}=\frac{0.7910}{0.6119}=1.2927 .
$$

Note that this value can be considered as the ratio $\operatorname{PCU}_{i}\left(x, x^{f}, y\right)=\frac{|c b|}{|o e|}$ since $|c a|=|o d|$.

If the output of point $a$ is increased from 4 to 4.5 , i.e., it now takes on position $a^{\prime}$ in Figure 3 , then the numerator in (7) increases to $D F_{i}^{S R}\left(x^{f}, x^{v}, y\right)=\frac{\left|c^{\prime} b^{\prime}\right|}{\left|c^{\prime} a^{\prime}\right|}=0.8823$ while the denominator remains unchanged. Consequently, the input-oriented capacity utilization also increases to:

$$
P C U_{i}\left(x, x^{f}, y\right)=\frac{D F_{i}^{S R}\left(x^{f}, x^{\nu}, y\right)}{D F_{i}^{S R}\left(x^{f}, x^{v}, 0\right)}=\frac{0.8823}{0.6119}=1.4418 .
$$

This new value corresponds with the ratio $P C U_{i}\left(x, x^{f}, y\right)=\frac{\left|c^{\prime} b^{\prime}\right|}{|o e|}$. Thus, we observe an increase of the input-oriented capacity utilization when the output is increased, which necessitates more inputs. This corresponds with intuition. However, as mentioned above, note that the input-oriented plant capacity measure never attains a maximum value in contrast to the output-oriented plant capacity measure. Thus, the input-oriented capacity measure does not measure capacity utilization with respect to some maximum, but with respect to the minimal amount of variable inputs compatible with zero outputs (i.e., minimal inputs needed to start producing nonzero outputs).

For completeness sake, the short run efficiencies and the corresponding PCU are computed for all initial observations, both for a convex and a nonconvex technology. The results are reported in Table 1 and already reveal that convex and nonconvex results need not be the same. 


\section{<TABLE 1 ABOUT HERE> \\ <FIGURE 3 ABOUT HERE>}

\section{EMPIRICAL ILLUSTRATION}

To illustrate the ease of implementing the plant capacity frameworks developed in this contribution, the decompositions (6) and (8) are computed using the data in Fan, Li and Weersink (1996). These data contain 471 specialised dairy farms from the province of Quebec in Canada. ${ }^{5}$ The single output is milk production per cow. The four inputs are: forage consumption; grain and concentrate consumption; value of capital stock; and labour-person units. These inputs are also expressed in units per cow. For the purpose of the analysis, the fixed inputs are capital and labour, and the variable inputs are forage consumption and grain and concentrate consumption.

Table 2 provides basic descriptive statistics for both the traditional output- and the new input-oriented decompositions (6) and (8), respectively, using both convex (upper part of table) and nonconvex (lower part of table) technologies. Apart from the percentage of efficient observation relative to the sample, we report the geometric average (to respect the multiplicative decomposition), the standard deviation, and the minima or maxima (bold faced) depending on the context.

\section{<TABLE 2 ABOUT HERE>}

Contrasting input and output orientations, we find $10.40 \%$ and $2.34 \%$ efficient observations for the radial efficiency measures, $3.40 \%$ and $2.34 \%$ efficient observations for the biased plant capacity, and $11.25 \%$ and $4.88 \%$ efficient observations for the unbiased plant capacity, respectively. In addition, the geometric average reveals an about $27 \%$ input-oriented inefficiency while it shows an about $17 \%$ output-oriented inefficiency. For the biased plant capacity measure, there is an about $40 \%$ input-oriented inefficiency compared to a $26 \%$ output-oriented inefficiency. Finally, for the unbiased plant capacity measure, one observes a $20 \%$ input-oriented capacity utilisation compared to an about $7 \%$ output-oriented capacity utilisation.

Switching focus on the differences between convex and nonconvex results, several findings stand out. First, the percentage of efficient observations is equal or higher for the radial efficiency measures, the biased plant capacity, as well as the unbiased plant capacity. Second, also the level of efficiency, and the level of biased plant capacity is higher. For the unbiased plant capacity, the input-oriented level of biased plant capacity is higher, but the output-oriented one is slightly lower. The latter result is possible because the unbiased plant capacity measure is a ratio of two efficiencies both of which can be ordered. While these empirical findings are overall in line with

\footnotetext{
${ }^{5}$ We maintain all observations rather than opting for a preliminary screening looking for any potential outliers.
} 
expectations, these results once more highlight the impact of convexity on plant capacity utilisation results.

Figure 4 contains four boxplot subfigures summarizing the distributions of the (a) inputoriented convex results; (b) output-oriented convex results; (c) input-oriented nonconvex results; and (d) output-oriented nonconvex results. Recall that this boxplot graphically displays a fivenumber summary containing the "minimum", the lower hinge, the median, the upper hinge, and the "maximum". The length of the box between both hinges represents the interquartile range, while the vertical line in the center marks the median. The length of the whiskers denoting the range is here drawn no longer than 1.5 times the length of the box, such that points plotted beyond the whiskers are potential outliers and indicate tails heavier than the normal distribution.

In addition to the descriptive statistics highlighted above, these boxplots reveal some skewness in some of the efficiency measures and plant capacity measures, as well as the existence of a limited number of potential outliers. In particular, both the position of the median within the box and the relative length of both whiskers suggest skewed distributions for most efficiency measures and plant capacity measures, except for the Biased PCU in subfigure (a). In addition, some to several points plotted beyond the whiskers reveal heavy tails compared to the normal distribution for most efficiency measures and plant capacity measures, except for the Biased PCU in subfigure (c).

\section{<FIGURE 4 ABOUT HERE>}

Table 3 reports on the first line the Spearman rank correlation coefficients for some components of the output- and input-oriented decompositions (6) and (8). First, input- versus output-oriented components are compared given convexity and nonconvexity, respectively. Correlations are moderately high for the PCU component, which is our central interest. Then, convex versus nonconvex components are compared given input-orientation and outputorientation, respectively. The rank correlations are now rather high for the PCU component. Thus, input- and output-orientations seem to differ more than convex and nonconvex results.

The same Table 3 also reports on the second line the results of a formal test statistic proposed by $\mathrm{Li}$ (1996). ${ }^{6}$ The null hypothesis of this Li-test states that both distributions are equal for a given efficiency score and underlying specification of technology. A glance at Table 3 reveals that one can safely reject the null hypothesis of equal distributions for all cases. Thus, input- as well as output-oriented and convex as well as nonconvex radial efficiency measures, biased and unbiased plant capacities are significantly different from one another.

\footnotetext{
${ }^{6}$ This test is valid for both dependent and independent variables. Note that dependency is a characteristic of frontier estimators: efficiency levels depend on sample size, among others.
} 
<TABLE 3 ABOUT HERE>

\section{CONCLUSIONS}

This paper introduces a new input-oriented plant capacity measure that complements the existing output-oriented plant capacity measure. Instead of focusing on maximal outputs for given fixed inputs and unlimited amounts of variable outputs, it focuses on reducing variable inputs for given fixed inputs compatible with an output level of zero. Thus, it measures plant capacity in relation to the minimal variable inputs at which production at positive output levels starts.

A numerical example serves to illustrate the geometric intuition behind this new inputoriented plant capacity measure. An empirical illustration using specialised Canadian dairy farms underscores the differences and similarities between the input- and output-oriented plant capacity measures. It also emphasises the impact of choosing either a convex or a nonconvex technology, confirming the earlier conclusion of Walden and Tomberlin (2010) that convexity matters for estimating plant capacity.

This new definition enlarges the empirical toolbox for practitioners. It also offers a natural framework when addressing questions whereby capacity is phrased in terms of the inputs. For instance, the increasing share of internet banking as well as new payment systems (e.g., based on smart phone applications) decreases the capacity utilisation of existing bank branches. This will ultimately lead to new questions on the optimal configuration of bank networks in either more or less the same number, but smaller branches, or more geographically concentrated branches of about the same size.

\section{REFERENCES}

Briec, W., K. Kerstens, D. Prior, I. Van de Woestyne (2010) Tangency Capacity Notions Based upon the Profit and Cost Functions: A Non-Parametric Approach and a Comparison, Economic Modelling, 27(5), 1156-1166.

Bye, T., A. Bruvoll, J. Larsson (2009) Capacity Utilization in a Generalized Malmquist Index Including Environmental Factors: A Decomposition Analysis, Land Economics, 85(3), 529-538.

Cassels, J.M. (1937) Excess Capacity and Monopolistic Competition, Quarterly Journal of Economics, 51(3), 426-443.

Caves, R.E. (2007) In Praise of the Old I.O., International Journal of Industrial Organization, 25(1), $1-12$. 
De Borger, B., K. Kerstens (2000) The Malmquist Productivity Index and Plant Capacity Utilization, Scandinavian Journal of Economics, 102(2), 303-310.

De Borger, B., K. Kerstens, D. Prior, I. Van de Woestyne (2012) Static Efficiency Decompositions and Capacity Utilisation: Integrating Technical and Economic Capacity Notions, Applied Economics, 44(31), 4125-4141.

Dervaux, B., K. Kerstens, H. Leleu (2000) Remedying Excess Capacities in French Surgery Units by Industry Reallocations: The Scope for Short and Long Term Improvements in Plant Capacity Utilization, in: J.L.T. Blank (ed) Public Provision and Performance: Contributions from Efficiency and Productivity Measurement, Amsterdam, Elsevier, 121-146.

Fan, Y., Q. Li, A. Weersink (1996) Semiparametric Estimation of Stochastic Production Frontier Models, Journal of Business \& Economic Statistics, 14(4), 460-468.

Färe, R. (1984) The Existence of Plant Capacity, International Economic Review, 25(1), 209-213.

Färe, R., S. Grosskopf, E. Kokkelenberg (1989) Measuring Plant Capacity, Utilization and Technical Change: A Nonparametric Approach, International Economic Review, 30(3), 655-666.

Färe, R., S. Grosskopf, V. Valdmanis (1989) Capacity, Competition and Efficiency in Hospitals: A Nonparametric Approach, Journal of Productivity Analysis, 1(2), 123-138.

Färe, R., S. Grosskopf, C.A.K. Lovell (1994) Production Frontiers, Cambridge, Cambridge University Press.

Felthoven, R.G. (2002) Effects of the American Fisheries Act on Capacity, Utilization and Technical Efficiency, Marine Resource Economics, 17(3), 181-205.

Ghemawat, P., B. Nalebuff (1985) Exit, Rand Journal of Economics, 16(2), 184-194.

Hackman, S.T. (2008) Production Economics: Integrating the Microeconomic and Engineering Perspectives, Berlin, Springer.

Hickman, B.G. (1964) On a New Method for Capacity Estimation, Journal of the American Statistical Association, 59(306), 529-549.

Jamasb, T., M. Pollitt (2001) Benchmarking and Regulation: International Electricity Experience, Utilities Policy, 9(3), 107-130.

Johansen, L. (1968) Production Functions and the Concept of Capacity, Namur, Recherches Récentes sur la Fonction de Production (Collection "Economie Mathématique et Econometrie", $\mathrm{n}^{\circ} 2$ ) [reprinted in F.R. Førsund (ed.) (1987) Collected Works of Leif Johansen, Volume 1, Amsterdam, North Holland, 359-382].

Karagiannis, R. (2015) A System-of-Equations Two-Stage DEA Approach for Explaining Capacity Utilization and Technical Efficiency, Annals of Operations Research, 227(1), 25-43. 
Kerr, C.A., J.C. Glass, G.M. McCallion, D.G. McKillop (1999) Best-Practice Measures of Resource Utilization for Hospitals: A Useful Complement in Performance Assessment, Public Administration, 77(3) 639-650.

Kerstens, K., N. Vestergaard, D. Squires (2006) A Short-Run Johansen Industry Model for CommonPool Resources: Planning a Fishery's Industrial Capacity to Curb Overfishing, European Review of Agricultural Economics, 33(3), 361-389.

Kirkley, J., C.J. Morrison Paul, D. Squires (2002) Capacity and Capacity Utilization in Common-pool Resource Industries, Environmental and Resource Economics, 22(1-2), 71-97.

Klein, L.R. (1960) Some Theoretical Issues in the Measurement of Capacity, Econometrica, 28(2), 272-286.

Li, Q. (1996) Nonparametric Testing of Closeness between Two Unknown Distribution Functions, Econometric Reviews, 15(1), 261-274.

Liu, J.S., L.Y.Y. Lu, W.-M. Lu, B.J.Y. Lin (2013) A Survey of DEA Applications, Omega, 41(5), 893-902.

Magnussen, J., L. Rivers Mobley (1999) The Impact of Market Environment on Excess Capacity and the Cost of an Empty Hospital Bed, International Journal of the Economics of Business, 6(3), 383-398.

Nelson, R. (1989) On the Measurement of Capacity Utilization, Journal of Industrial Economics, 37(3), 273-286.

Sahoo, B.K., K. Tone (2009) Decomposing Capacity Utilization in Data Envelopment Analysis: An Application to Banks in India, European Journal of Operational Research, 195(2), 575-594.

Segerson, K., D. Squires (1990) On the Measurement of Economic Capacity Utilization for MultiProduct Industries, Journal of Econometrics, 44(3), 347-361.

Segerson, K., D. Squires (1995) Measurement of Capacity Utilization for Revenue-Maximizing Firms, Bulletin of Economic Research, 47(1), 77-85.

Sherman, H.D., G. Ladino (1995) Managing Bank Productivity Using Data Envelopment Analysis (DEA), Interfaces, 25(2), 60-73.

Squires, D. (1987) Long-Run Profit Functions for Multiproduct Firms, American Journal of Agricultural Economics, 69(3), 558-569.

Tone, K., B.K. Sahoo (2003) Scale, Indivisibilities and Production Function in Data Envelopment Analysis, International Journal of Production Economics, 84(2), 165-192.

Valdmanis, V., P. Bernet, J. Moises (2010) Hospital Capacity, Capability, and Emergency Preparedness, European Journal of Operational Research, 207(3), 1628-1634. 
Valdmanis, V., L. Kumanarayake, J. Lertiendumrong (2004) Capacity in Thai Public Hospitals and the Production of Care for Poor and Nonpoor Patients, Health Services Research, 39(6p2), 2117-2134.

Van Hoof, L., J.W. De Wilde (2005) Capacity Assessment of the Dutch Beam-trawler Fleet using Data Envelopment Analysis (DEA), Marine Resource Economics, 20(4), 327-345.

Vestergaard, N., D. Squires, J. Kirkley (2003) Measuring Capacity and Capacity Utilization in Fisheries: The Case of the Danish Gill-Net Fleet, Fisheries Research, 60(2-3), 357-368.

Walden, J.B., D. Tomberlin (2010) Estimating Fishing Vessel Capacity: A Comparison of Nonparametric Frontier Approaches, Marine Resource Economics, 25(1), 23-36.

Yagi, M., S. Managi (2011) Catch Limits, Capacity Utilization and Cost Reduction in Japanese Fishery Management, Agricultural Economics, 42(5), 577-592. 
Table 1: Numerical Example: Input-Oriented Plant Capacity Utilization for Convex (C) and Nonconvex (NC) Technologies

\begin{tabular}{rrrrrcccccc}
\hline \multicolumn{1}{c}{} & \multicolumn{9}{c}{$D F_{i}^{S R}\left(x^{f}, x^{v}, y\right)$} & \multicolumn{2}{c}{$D F_{i}^{S R}\left(x^{f}, x^{v}, 0\right)$} & \multicolumn{2}{c}{$P C U_{i}\left(x, x^{f}, y\right)$} \\
\hline Nr. & $x^{f}$ & \multicolumn{1}{c}{$x_{1}^{v}$} & \multicolumn{1}{c}{$x_{2}^{v}$} & \multicolumn{1}{c}{$y$} & $\mathrm{C}$ & $\mathrm{NC}$ & $\mathrm{C}$ & $\mathrm{NC}$ & $\mathrm{C}$ & $\mathrm{NC}$ \\
\hline 1 & 2 & 1.0 & 7.0 & 3 & 1.0000 & 1.0000 & 1.0000 & 1.0000 & 1.0000 & 1.0000 \\
2 & 2 & 3.0 & 6.0 & 3 & 0.8542 & 1.0000 & 0.8542 & 1.0000 & 1.0000 & 1.0000 \\
3 & 2 & 3.5 & 6.5 & 3 & 0.7664 & 0.9231 & 0.7664 & 0.9231 & 1.0000 & 1.0000 \\
4 & 2 & 4.5 & 4.0 & 3 & 0.8723 & 1.0000 & 0.8723 & 1.0000 & 1.0000 & 1.0000 \\
5 & 2 & 5.0 & 4.5 & 3 & 0.7810 & 0.9000 & 0.7810 & 0.9000 & 1.0000 & 1.0000 \\
6 & 2 & 5.5 & 2.0 & 3 & 0.9535 & 1.0000 & 0.9535 & 1.0000 & 1.0000 & 1.0000 \\
7 & 2 & 6.0 & 1.0 & 3 & 1.0000 & 1.0000 & 1.0000 & 1.0000 & 1.0000 & 1.0000 \\
8 & 2 & 7.5 & 4.0 & 3 & 0.6308 & 0.7333 & 0.6308 & 0.7333 & 1.0000 & 1.0000 \\
9 & 3 & 3.0 & 9.5 & 5 & 1.0000 & 1.0000 & 0.6260 & 0.7368 & 1.5976 & 1.3571 \\
10 & 3 & 10.0 & 1.0 & 5 & 1.0000 & 1.0000 & 1.0000 & 1.0000 & 1.0000 & 1.0000 \\
11 & 3 & 4.5 & 9.0 & 5 & 0.9086 & 1.0000 & 0.5694 & 0.6667 & 1.5957 & 1.5000 \\
12 & 3 & 5.5 & 10.5 & 5 & 0.7651 & 0.8571 & 0.4795 & 0.5714 & 1.5955 & 1.5000 \\
13 & 3 & 6.5 & 6.5 & 5 & 0.9132 & 1.0000 & 0.5734 & 0.6923 & 1.5924 & 1.4444 \\
14 & 3 & 7.5 & 7.5 & 5 & 0.7914 & 0.8667 & 0.4970 & 0.6000 & 1.5924 & 1.4444 \\
15 & 3 & 9.0 & 5.0 & 5 & 0.8251 & 1.0000 & 0.5190 & 0.6111 & 1.5899 & 1.6364 \\
16 & 3 & 10.0 & 9.0 & 5 & 0.6216 & 0.7222 & 0.3905 & 0.4500 & 1.5920 & 1.6049 \\
\hline
\end{tabular}

Table 2: Descriptive Statistics of Efficiency Decompositions (6) and (8)

\begin{tabular}{crrrrrr}
\hline Convex & $D F_{i}^{S R}\left(x^{f}, x^{v}, y\right)$ & $D F_{i}^{S R}\left(x^{f}, x^{v}, 0\right)$ & $P C U_{i}\left(x, x^{f}, y\right)$ & $D F_{o}(x, y)$ & $D F_{o}\left(x^{f}, y\right)$ & $P C U_{o}\left(x, x^{f}, y\right)$ \\
\hline \% Ef. Obs. & $10.40 \%$ & $3.40 \%$ & $11.25 \%$ & $2.34 \%$ & $2.34 \%$ & $4.88 \%$ \\
Geom Avg & 0.7280 & 0.6056 & 1.2021 & 1.1690 & 1.2626 & 0.9259 \\
St. Dev. & 0.1430 & 0.1460 & 0.2686 & 0.1306 & 0.1725 & 0.0625 \\
Min./Max. & 0.3152 & 0.2672 & $\mathbf{3 . 6 4 4 3}$ & $\mathbf{1 . 7 4 2 9}$ & $\mathbf{2 . 0 8 4 9}$ & 0.5175 \\
\hline Nonconvex & $D F_{i}^{S R}\left(x^{f}, x^{v}, y\right)$ & $D F_{i}^{S R}\left(x^{f}, x^{v}, 0\right)$ & $P C U_{i}\left(x, x^{f}, y\right)$ & $D F_{o}(x, y)$ & $D F_{o}\left(x^{f}, y\right)$ & $P C U_{o}\left(x, x^{f}, y\right)$ \\
\hline \% Ef. Obs. & $34.82 \%$ & $8.49 \%$ & $22.51 \%$ & $34.82 \%$ & $9.13 \%$ & $14.01 \%$ \\
Geom Avg & 0.8584 & 0.7052 & 1.2172 & 1.0803 & 1.2101 & 0.8927 \\
St. Dev. & 0.1326 & 0.1517 & 0.2408 & 0.0990 & 0.1662 & 0.0845 \\
Min./Max. & 0.3721 & 0.3327 & $\mathbf{2 . 9 5 2 4}$ & $\mathbf{1 . 4 4 2 0}$ & $\mathbf{1 . 9 5 2 1}$ & 0.5366 \\
\hline
\end{tabular}

Table 3: Spearman Rank Correlations and Li-tests on Decompositions (6) and (8)

\begin{tabular}{crrrr}
\hline & & Efficiency & Biased PCU & Unbiased PCU \\
\hline Convex & Input vs. Output & -0.6793 & 0.2220 & 0.4963 \\
& & $46.82^{* * *} \dagger$ & $106.79^{* * *}$ & $37.80^{* * * *}$ \\
Nonconvex & Input vs. Output & -0.8678 & 0.0684 & 0.3681 \\
& & $2.82^{* * *}$ & $43.24^{* * *}$ & $32.27^{* * * *}$ \\
Input & C vs. NC & 0.8525 & 0.9371 & 0.7713 \\
& & $52.16^{* * *}$ & $23.56^{* * *}$ & $11.45^{* * * *}$ \\
Output & C vs. NC & 0.8092 & 0.9642 & 0.7216 \\
& & $49.47^{* * *}$ & $5.41^{* * *}$ & $24.53^{* * * *}$ \\
\hline
\end{tabular}

$\dagger \mathrm{Li}$ test: critical values at $1 \%$ level $=2.33\left(^{* * *}\right) ; 5 \%$ level $=1.64\left({ }^{* *}\right) ; 10 \%$ level $=1.28\left(^{*}\right)$. 
Figure 1: Total Product Curve with Input and Output-oriented Plant Capacity Measures

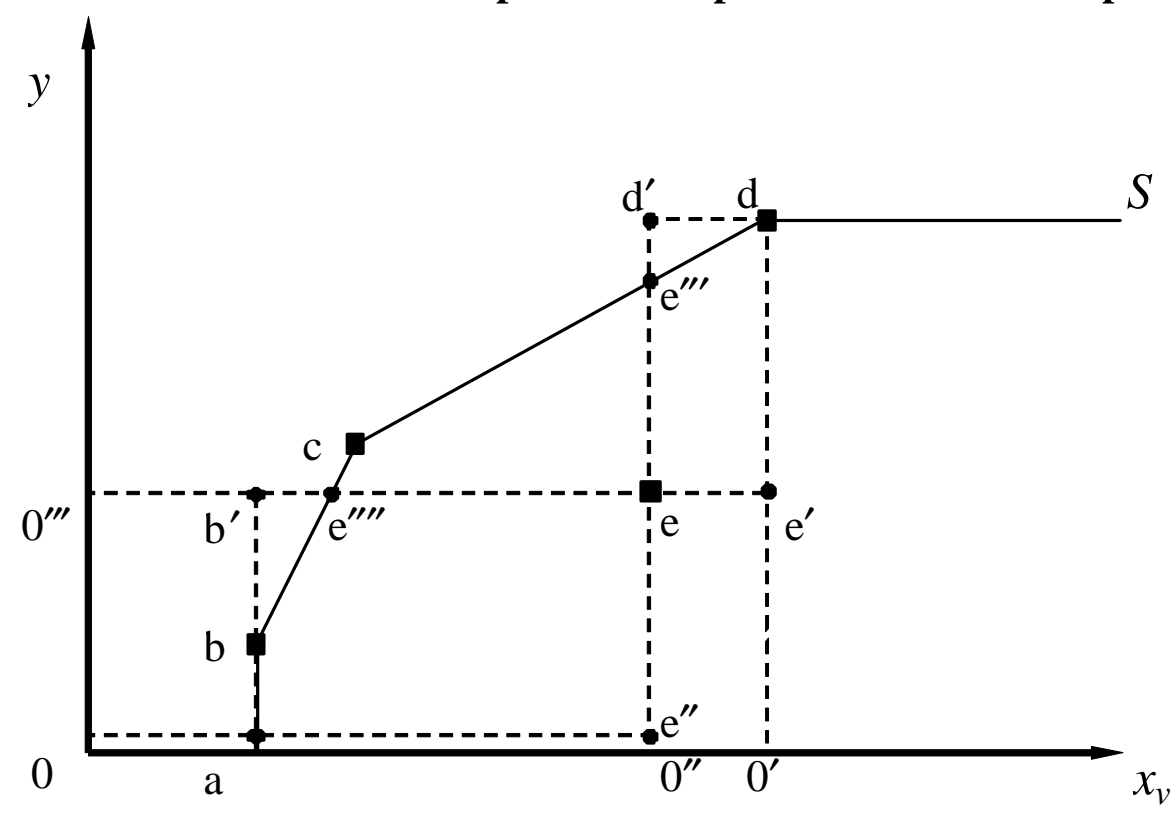

Figure 2: Isoquant with Input and Output-oriented Plant Capacity Measures

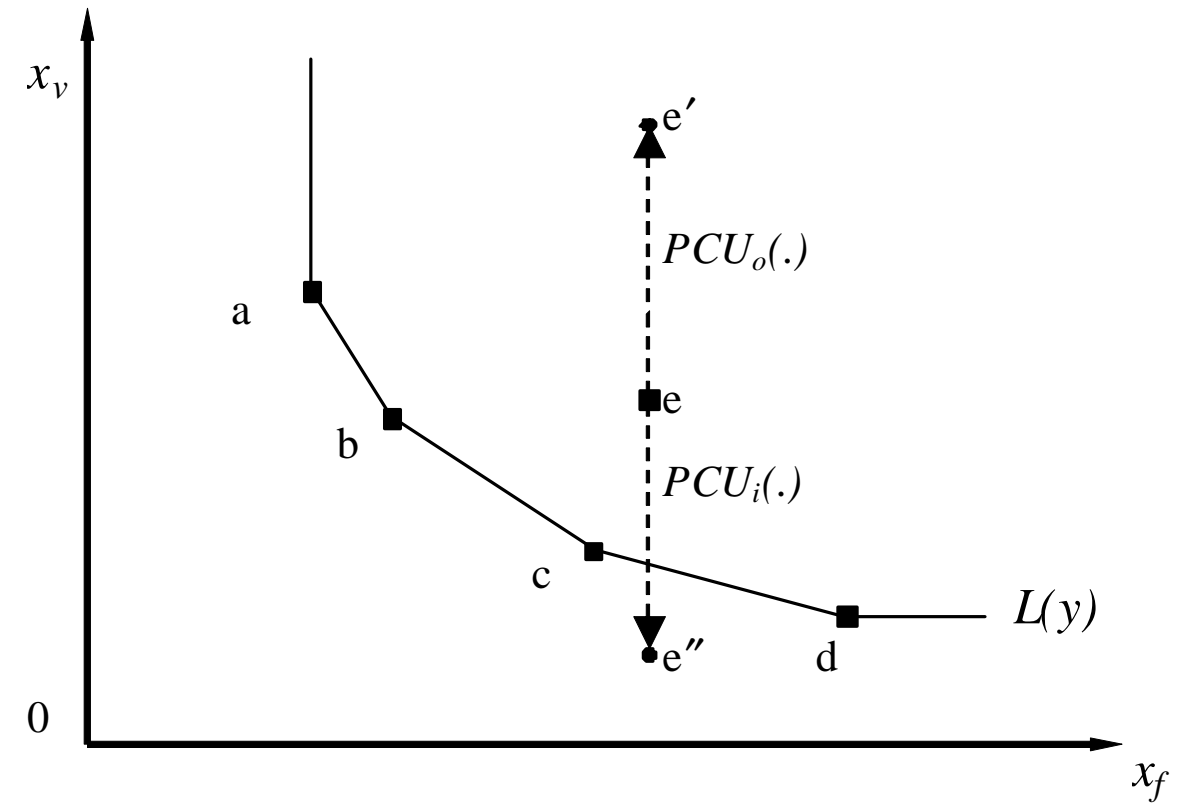


Figure 3: Efficient Frontier in Input-Output Space and Projections for a Particular Observation Illustrating the New Input-Oriented Plant Capacity Utilization Measure

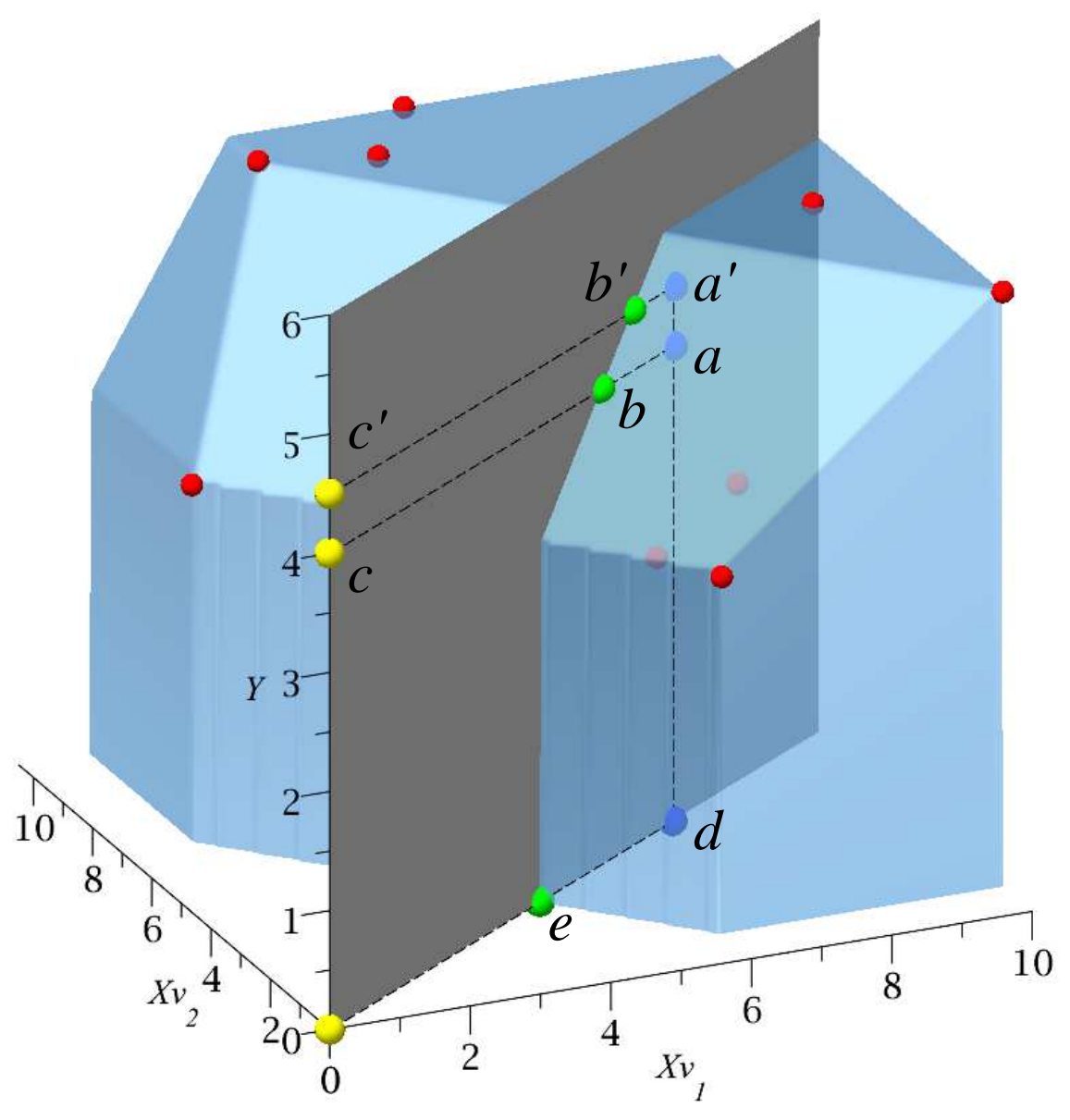


Figure 4: Boxplots of Efficiency Decompositions (6) and (8)

(a) Input-oriented \& Convex

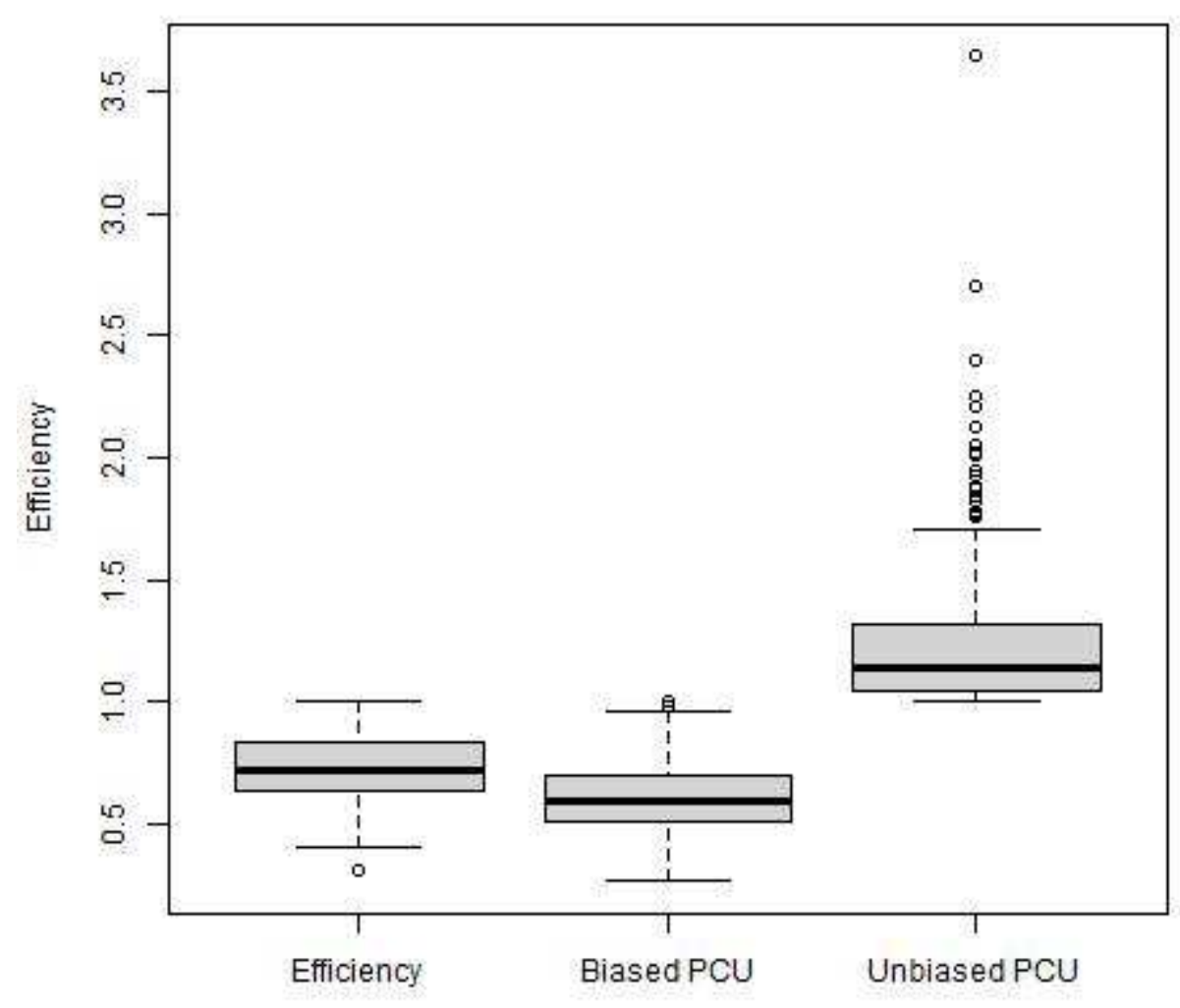

(b) Output-oriented \& Convex

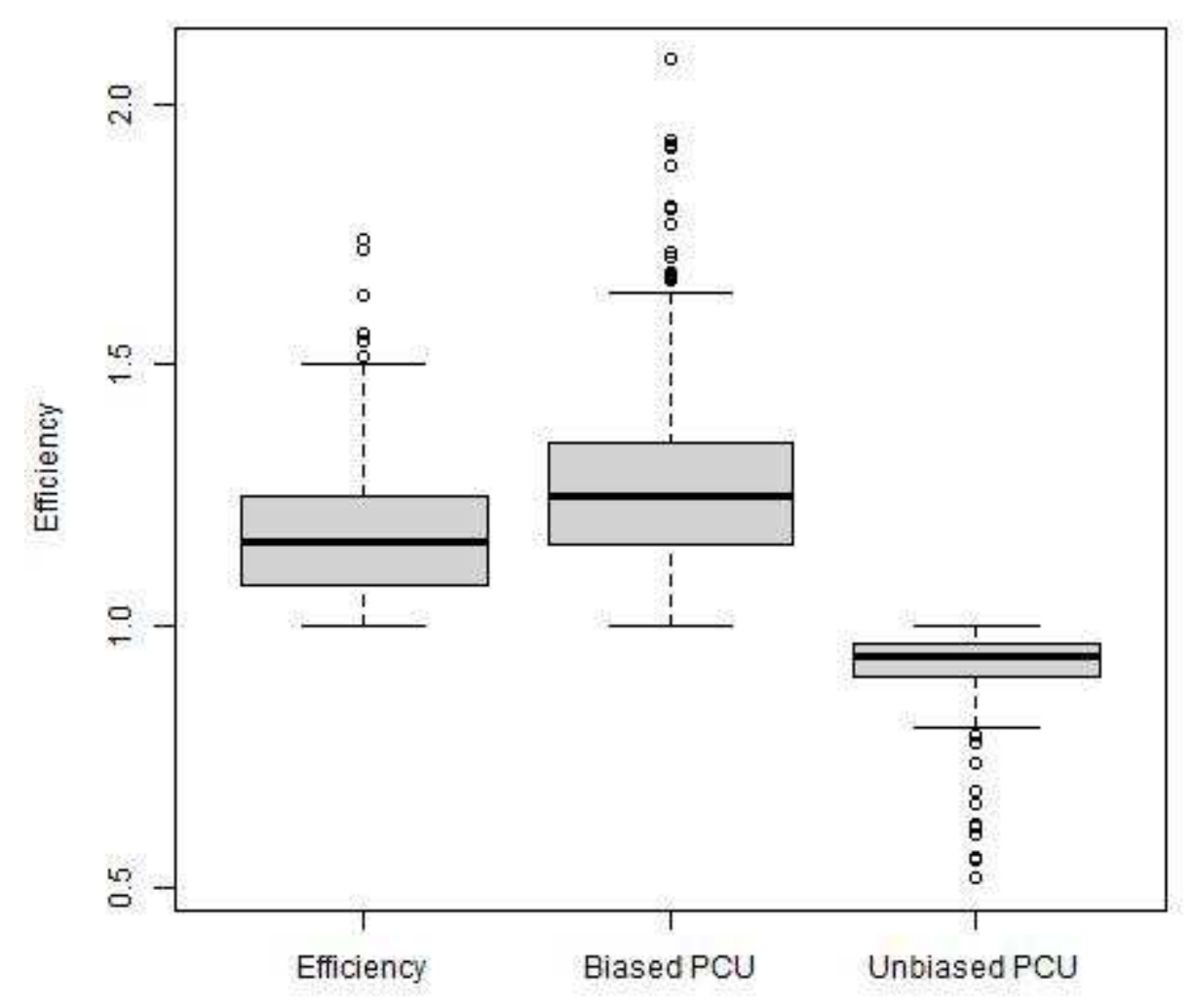


(c) Input-oriented \& Nonconvex

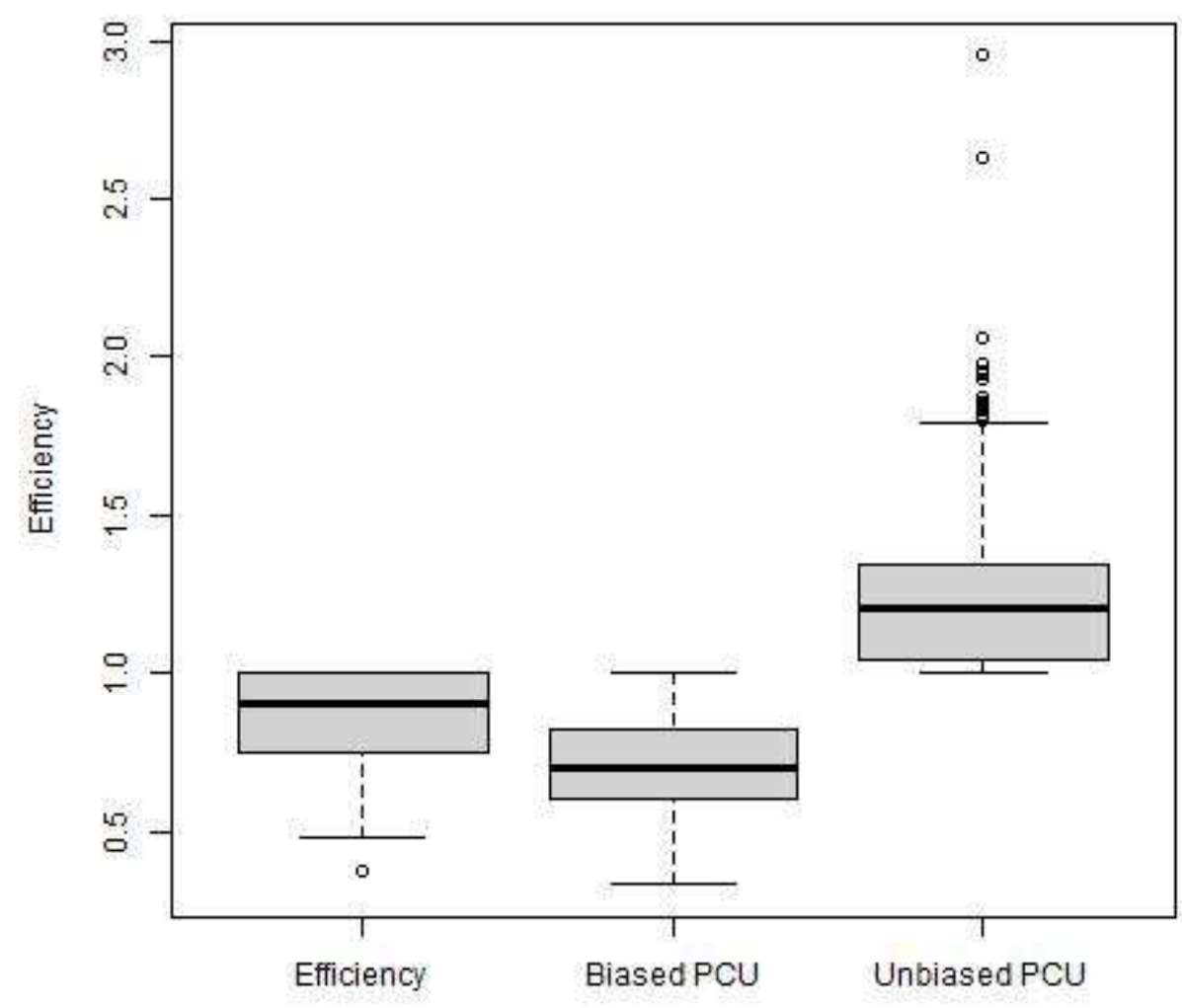

(d) Output-oriented \& Nonconvex

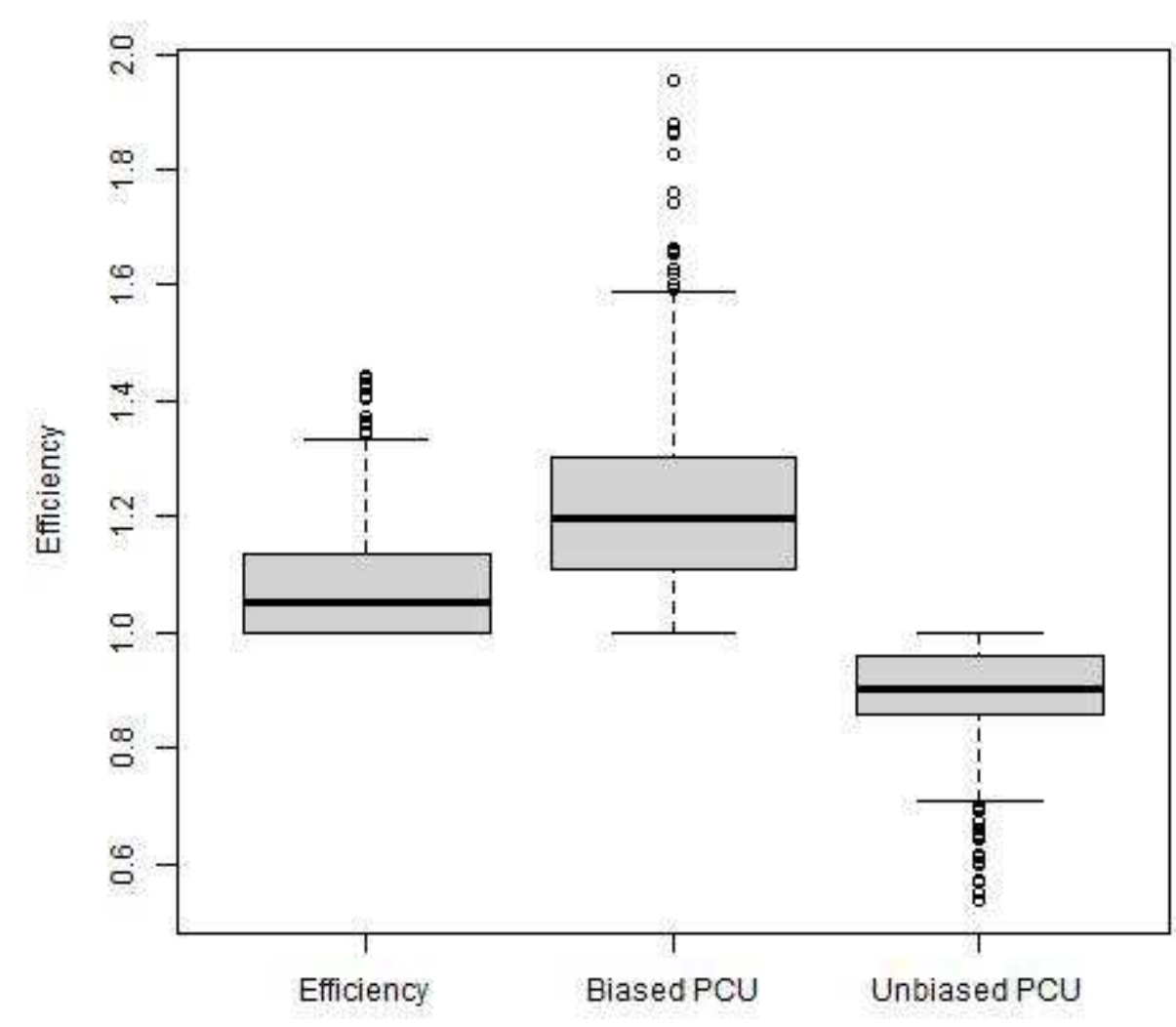

